\title{
Evaluating oil palm fresh fruit bunch processing in Nigeria
}

Kelechi E. Anyaoha ${ }^{a}$, Abdul M. Mouazen $^{\mathrm{b}}$, Ruben Sakrabani ${ }^{\mathrm{a}^{*}}$, Kumar Patchigolla $^{\mathrm{c}}$

${ }^{\mathrm{a} C}$ ranfield Soil and Agrifood Institute, School of Water, Energy and Environment, Cranfield University, MK43 OAL United Kingdom. Department of Soil Management, Ghent University, Coupure 653, 900 Gent, Belgium, 'Power Engineering Centre, Cranfield University, MK43 OAL United Kingdom.

*E-mail of corresponding: author: r.sakrabani@cranfield.ac.uk

\section{Abstract}

Three routes of oil palm fresh fruit bunch (FFB) processing in Nigeria namely, industrial, small-scale and traditional were compared by determining their fruit losses. The fruits not recovered after each process were hand-picked and quantified in terms of crude palm oil (CPO), palm kernel (PK), mesocarp fibre (MF), and palm kernel shell (PKS). The energy value of EFB, MF, and PKS were used to determine the value of energy lost for each route. The environmental implications of disposal of EFB were estimated, and socio-economics of the industrial and small-scale routes were related. The analysis showed that $29,18,75$, and $27 \mathrm{~kg}$ of $\mathrm{CPO}, \mathrm{PK}, \mathrm{MF}$, and PKS were lost for every $1000 \mathrm{~kg}$ of FFB processed with the industrial route, whereas $5.6,3.2,1.4$, and $5.1 \mathrm{~g}$ were lost with the small-scale route, respectively. Approximately $89 \mathrm{kWh}$ and $31 \mathrm{kWh}$ more energy was lost from MF and PKS, respectively, with the industrial route than the other two routes. An equivalent of 6,670 tons $\mathrm{CO}_{2}$-eq of methane and $\mathrm{N}_{2} \mathrm{O}$ released due to the disposal of 29000 tons of EFB from one oil palm mill. The value of lost CPO per $1000 \mathrm{~kg}$ of FFB using industrial route can offset the cost of processing $1000 \mathrm{~kg}$ of FFB using the small- 
scale route. The advantages of industrial route are high throughput and high quality CPO however, high losses are associated with it and therefore the FFB can be fed into the small-scale route, which offers a synergistic approach for both routes.

Keywords: fresh fruit bunch, oil palm, empty fruit bunch, mesocarp fibre, palm kernel shell, crude palm oil, palm kernel

\section{Introduction}

Oil palm (Elaeis guineensis) is generally believed to originate from West Africa and the most important source of edible oil in most part of West Africa. Indonesia and Malaysia are the largest producers of palm oil from oil palm tree in the world (Zainal et al. 2016) and Nigeria the fifth largest producer after Thailand and Colombia (FAOSTAT 2017). Oil palm produces fruits in bunches and a bunch is known as fresh fruit bunch (FFB). The main products of oil palm industry are crude palm oil (CPO), and palm kernel (PK) which yields another type of oil known as palm kernel oil (PKO) and residue known as palm kernel cake (PKC). The wastes generated from processing FFB are known as FFB wastes. The solid wastes include palm kernel shell (PKS), empty fruit bunch (EFB), and mesocarp fibre (MF), which represent important biomasses in the oil palm industry (Kabir et al. 2017).

Global palm oil production in 2014 has been estimated to be 57 million tons according to FAOSTAT (2017). For every $1 \mathrm{~kg}$ of palm oil produced, $1.3 \mathrm{~kg}$ of FFB wastes were produced (Sulaiman et al. 2011), therefore the total FFB wastes produced in 2014 was 75 million tons. The equivalent of 7.9 million tons of CPO, 4.7 million tons of PK, 20.9 million tons of MF, 7.5 million tons of PKS and 22.8 million tons of EFB were produced globally in 2014, respectively. Another important waste 
of the industry is palm oil mill effluent (POME) which comprises all the liquid wastes generated in the oil palm mills. As the demand for palm oil increases, wastes generation also follows suit.

Most palm oil producing nations in Africa are known for their traditional techniques in FFB processing compared to the world's leading producers Indonesia and Malaysia. The identified processing routes in Nigeria are classified into large scale (industrial route), small-scale and subsistence (traditional) routes. Taiwo et al. (2000), reported that the industrial route is about $23 \%$ of FFB production in Nigeria while $77 \%$ is by small-scale and traditional routes. The industrial route (I) is characterised by the use of large-scale facilities, high throughput and high quality palm oil (in terms of low free fatty acids). The bunch is sterilized using steam with fruits still attached to it. The small-scale route (S) utilizes lower technology, but more than the traditional route and less quality oil (for human consumption) according to Taiwo et al. (2000) than the traditional route $(T)$. It is tedious and time consuming. The bunch in small-scale route is usually first quartered to allow for quick fermentation. The traditional route is employed by families using manual labour to process FFB for the palm oil consumed by the individual families, the excess palm oil is usually sold and therefore of very low throughput. The bunch in the traditional route is usually first separated into stalk and spikelets to allow for quick fermentation. Industrial route is known to have increased productivity as well as improved quality of palm oil giving the ability of processors to process fruits the same day they are harvested, hence the production capacity of Indonesia and Malaysia. However, there are challenges associated with the industrial route in regards to utilisation of the solid wastes: first, low bulk density, and high moisture content of EFB (60 - $70 \%$ ) according to Aziz et al. (2017) from industrial route which will requires enormous 
amount of energy to dry and reduce its size to fit into most existing boilers. Secondly, the EFB from the thresher also absorbs oil from the fruits during the threshing operation with a maximum of $4 \%$ oil (personal communication) acceptable by the processors. These challenges lead to EFB preferably dumped at the plantations. Thirdly, fruits remaining with the EFB constitutes lost materials and as well makes EFB a poor-quality fuel. Babatunde et al. (1988) reported that fruits not detached from the threshed bunches are discarded as wastes and therefore contribute to low CPO yield of the mills. According to Taiwo et al. (2000) delays in the traditional route also leads to the loss of enormous amount of fruits. Ali et al. (2014) have shown that about $92 \%$ of the fruits were recovered when chopped FFBs were used against about $46 \%$ with un-chopped FFB. Additionally, Babatunde et al. (1988) demonstrated that all fruits were recovered when chopped FFB spikelets were sterilized at $130{ }^{\circ} \mathrm{C}$ and steam pressure of 2.66 atmosphere for 30 minutes. On the other hand, $95 \%$ of fruits were recovered when un-chopped FFBs was sterilized at same temperature and pressure after 50 minutes.

Husain et al. (2003) reported that the calorific value of MF and PKS could be improved by reducing the moisture contents, which also applies to EFB. Fuels of high moisture content and low bulk density are difficult to use in most boilers; therefore, these factors influence efficient utilisation of EFB compared with PKS and MF especially as fuel. The complexities involve in size and moisture reduction, specifically the utilisation of EFB stem from the processing routes. As the value of the wastes increases, and the necessity for the use of biomass against fossil fuel, emphasis is placed on ensuring maximum value is derived during processing of FFB. This will involve ensuring that EFB from processing FFB are of high quality and that 
$\mathrm{CPO}, \mathrm{PK}, \mathrm{MF}$ and PKS are maximally recovered through the fruits during FFB processing. There are increasing research on energy use of EFB, MF, and PKS for energy purposes (Aziz et al. 2017; Kabir et al. 2017; Lee et al. 2017; Shahbaz et al. 2017), however, there is limited report on how the processing of FFB affects the quality of EFB as fuel, and the study of the three processing routes in terms of CPO, PK, MF and PKS yield.

Therefore, the objectives of this study are 1) to determine how FFB processing routes affect fruit losses, 2) to determine environmental and socioeconomic implications of the different processing routes especially on EFB utilisation as fuel, and 3) to make recommendation on reducing fruit and EFB losses from FFB processing.

\section{Materials and Methods}

Data collection

Two mills (industrial routes), each 60 tonshour $^{-1}$ and 30 tonshour $^{-1}$ mills, respectively, and one small-scale mill of about 0.6 tonshour $^{-1}$ (small-scale route) which are in South Eastern region of Nigeria (Figure 1) were visited in 2015 and 2016. The two mills on the industrial routes are the largest and only mills of 30 tonshour $^{-1}$ and above within 100 square kilometres of any of the two locations. In addition, three families were visited during their traditional palm fruit milling (traditional route). Currently, the 60 tonshour $^{-1}$ mill gets supply of FFB from the surrounding areas in addition to harvest from their plantations, therefore the palm oil and wastes from the area are mixture of the three varieties of oil palm (Dura, Pisifera and Tenera) which are available within the study area. Figure 2 represents the flow chats of industrial, small-scale and traditional routes of processing FFB showing points of wastes 
generation. The basic processes for all the routes include sterilization, stripping, fruit digestion, oil extraction and oil clarification.

These three processing routes of FFB were investigated at each of the mill to determine fruits losses associated with the three routes. For the industrial route, approximately $1548 \mathrm{~kg}$ of FFB was weighed (Table 1). On each day of data collection for the industrial route, FFB were randomly weighed before and after sterilization. Sterilized FFB threshed using the industrial thresher were randomly weighed and each of them manually threshed to recover the fruits left after the mechanical threshing. The recovered fruits were weighed and recorded. 
Figure 1

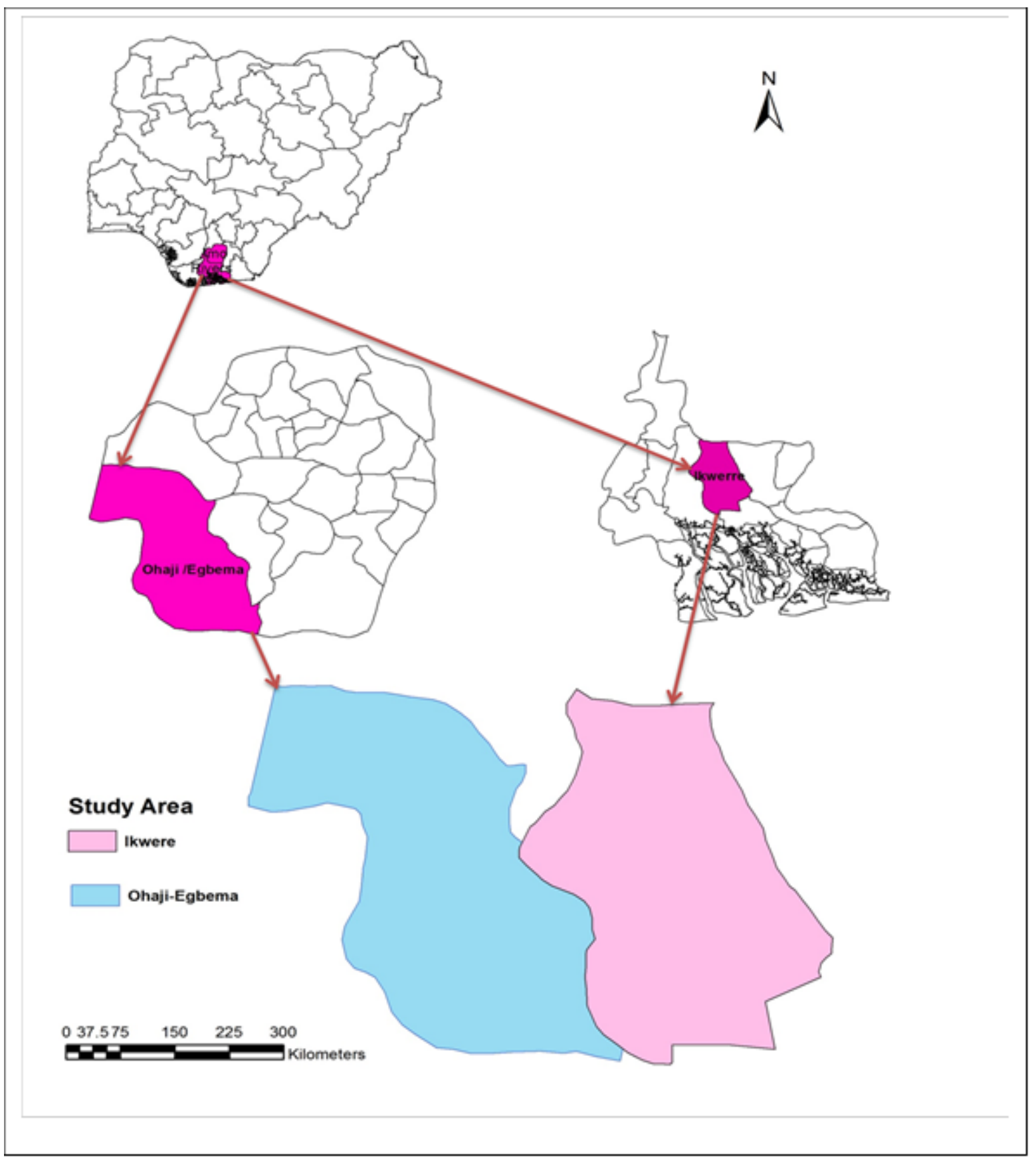

In the small-scale route, the FFB were weighed (Table 1) after reception in the mill and were later quartered. After four days when the fruits have become 
detachable from the spikelets, the quartered bunches were threshed using hammer. Fruits left after threshing the quartered bunches were manually picked. The recovered fruits and empty quartered bunches were weighed and recorded. In the traditional route, the FFB were weighed before the separation of EFB into bunch stalk and bunch spikelets (BS). After four days, the fruits were manually removed from the spikelets. Fruits left with the spikelets were carefully picked and weighed. On each route the measurements were taken during the usual FFB processing by the processors without their knowledge of why the measurements. The measurement was carried out using Camry Emperors weighing balance. The unstripped fruits left with the bunch/spikelets are considered lost because there is no system to recover them without losing CPO, MF, PKS, and PK derivable from the fruits, which are important products. Comparisons were made to determine the significance of the lost fruits for each processing route using analysis of variance carried out using Statistica 12 software (Dell - USA).

Air-dried samples of EFB, MF, and PKS sourced from the small-scale mill visited in South Eastern Nigeria were taken to Cranfield University, United Kingdom and were stored at room temperature in sealed containers for 6 months. The oil palm trees are 9- 29 years old. The EFB, MF, and PKS were later taken to Marchwood Scientific Services (external laboratory) Southampton United Kingdom, for the determination of the low heating value. The bulk densities of EFB, MF and PKS were measured as received from the 60 tonhour-1 mill using a $0.0178 \mathrm{~m}^{3}$ cylindrical container (0.285 m diameter and $0.279 \mathrm{~m}$ height) for PKS and MF, and a $0.145 \mathrm{~m}^{3}$ cylindrical container ( $0.57 \mathrm{~m}$ diameter and $0.57 \mathrm{~m}$ height) for EFB. 
Figure 2

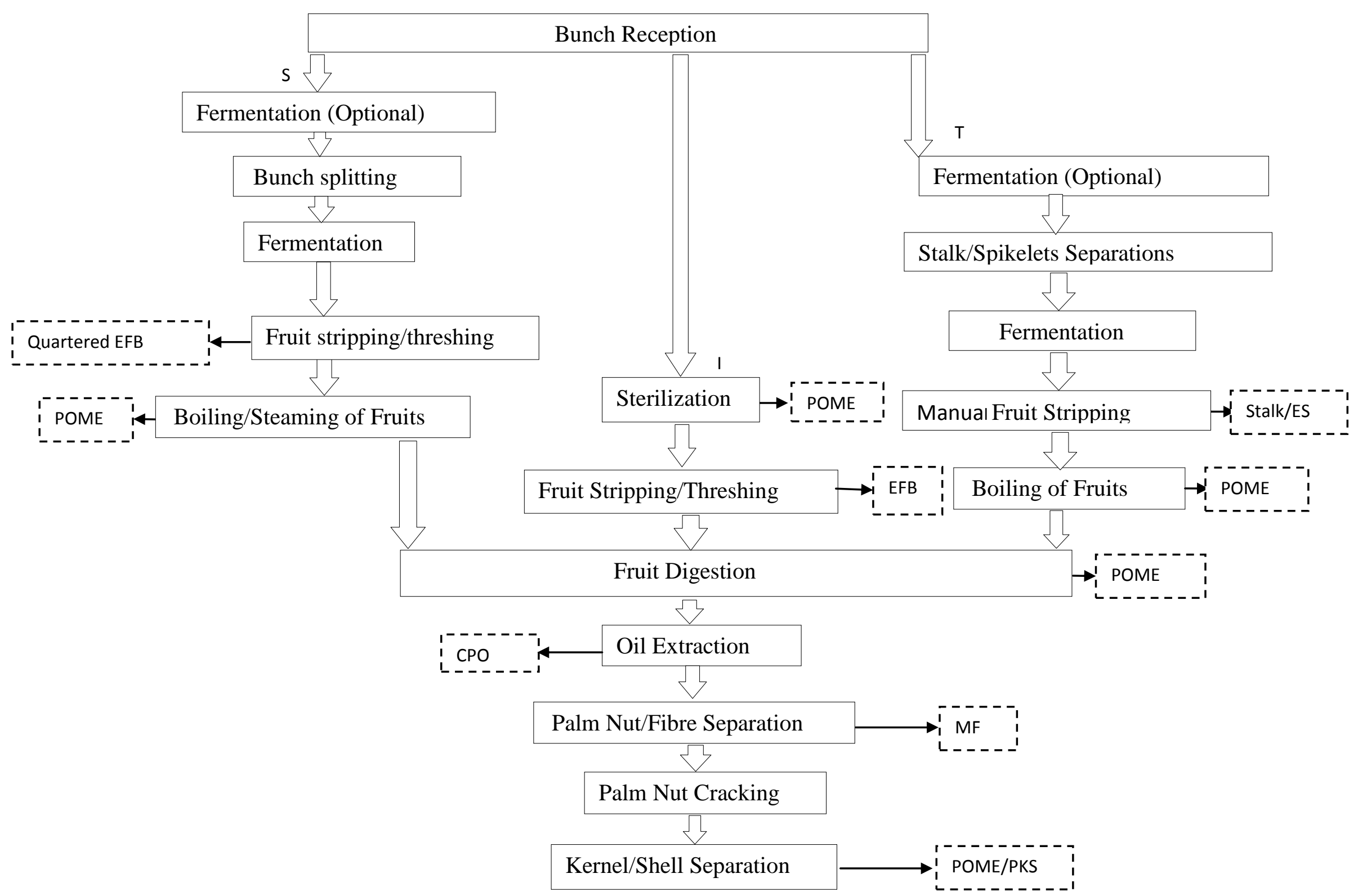


Table 1 Total weight of fresh fruit bunch (FFB) and total weight of recovered fruits (TWRF) from industrial (I), small-scale (S) and traditional (T) routes of FFB processing

\begin{tabular}{llllllllll}
\hline \multirow{2}{*}{$\begin{array}{l}\text { Day } \\
\text { number }\end{array}$} & \multicolumn{3}{c}{ Number of FFB weighed } & \multicolumn{3}{c}{ Total weight of FFB $(\mathrm{kg})$} & \multicolumn{3}{c}{ TWRF $(\mathrm{kg})$} \\
\cline { 2 - 10 } & $\mathrm{I}$ & $\mathrm{S}$ & $\mathrm{T}$ & $\mathrm{I}$ & $\mathrm{S}$ & $\mathrm{T}$ & $\mathrm{I}$ & $\mathrm{S}$ & $\mathrm{T}$ \\
\hline 1 & 11 & 27 & 6 & 129.11 & 236.25 & 52.75 & 25.60 & 0.0096 & 0.0001 \\
2 & 12 & 35 & 11 & 189.15 & 318.92 & 93.50 & 42.80 & 0.0056 & 0.0018 \\
3 & 11 & 21 & 6 & 137.40 & 168.08 & 50.43 & 34.90 & 0.0101 & 0.0011 \\
4 & 11 & 18 & 15 & 113.50 & 180.72 & 121.68 & 26.80 & 0.0144 & 0.0072 \\
5 & 14 & 40 & 6 & 190.03 & 240.58 & 54.03 & 56.30 & 0.0064 & 0.0009 \\
6 & 17 & 20 & 10 & 199.33 & 180.34 & 90.08 & 58.20 & 0.016 & 0.0014 \\
7 & 14 & 28 & 8 & 164.48 & 263.23 & 60.73 & 41.50 & 0.0134 & 0.0026 \\
8 & 13 & 42 & 10 & 137.20 & 294.56 & 85.80 & 47.40 & 0.0134 & 0.0032 \\
9 & 12 & 33 & 15 & 117.05 & 297.78 & 119.35 & 26.90 & 0.0158 & 0.0048 \\
10 & 15 & 20 & 4 & 170.50 & 178.85 & 40.73 & 55.20 & 0.0086 & 0.0023 \\
Total & 130 & 284 & 91 & 1547.74 & 2359.31 & 769.06 & 415.60 & 0.1133 & 0.0254 \\
\hline
\end{tabular}


Losses of different processing routes

The fruits left with EFB after FFB processing for each of the processing routes were weighed and quantified in terms of $\mathrm{CPO}, \mathrm{PK}, \mathrm{MF}$, and PKS lost using the percentage of processed FFB for each of CPO, MF, PK, and PKS according to Ohimain et al. (2013). The average values of CPO, MF, PK, and PKS in $\mathrm{kg}$ not recovered were calculated for every $1000 \mathrm{~kg}$ of FFB processed for each of the processing route using the expressions of equations 2.1 and 2.2 :

$$
f=\left(1000^{*} o^{\prime}\right) q^{-1}
$$

$$
O^{\prime}=\left(Y^{*} T\right) 100^{-1}
$$

$f$ represent values of $\mathrm{CPO}, \mathrm{PK}, \mathrm{MF}$, and PKS each lost for every $1000 \mathrm{~kg}$ processed for each route (Table 2) in $\mathrm{kg}, \mathrm{Y}$ is percentage yield of $\mathrm{CPO}, \mathrm{PK}, \mathrm{MF}$, and PKS from FFB processing. $T$ is total weight of recovered fruits and $q$ represent the total weight of FFB processed for each day of operation (Table 1).

Energy losses associated with each processing route The value of $15825 \mathrm{kJkWh}-1$ was used as representative heat rate for biomasses (Mayhead 2010) and with the lower heating values of EFB, MF and PKS respectively, the values of MF and PKS for $1 \mathrm{~kg}$ of fuel was estimated in kilowatthour (kWh). The lower heating values were determined using an external laboratory in United Kingdom. 
Economic Analysis

The economic analysis was carried out for the small-scale route with emphasis on the labour cost and value of CPO. The different tasks are divided into i) quartering, ii) dusting and loading, iii) threshing, dusting and loading, iv) water supply and firing, v) digestion/pressing, and vi) fibre/nut separation. The total costs as calculated were only the costs of labour for each of the tasks.

\section{Results and Discussion}

Fresh fruit bunch losses

The total weight of recovered fruits (TWRF) from industrial, small-scale and traditional routes of FFB processing are presented in Table 1, while the average values of CPO, MF, PK, and PKS in kg lost for every $1000 \mathrm{~kg}$ of FFB processed are presented in Table 2. Results of the analysis of variance for the losses associated with industrial, small-scale, and traditional routes are presented in Table 3. The $\mathrm{CPO}, \mathrm{PK}, \mathrm{MF}$, and PKS lost using the industrial route are significantly higher $(p<0.05)$ than in the small-scale and traditional routes. Results showed on the average that $28.93 \mathrm{~kg}$ of CPO, $16.72 \mathrm{~kg}$ of PK, $74.59 \mathrm{~kg}$ of MF, and $26.54 \mathrm{~kg}$ of PKS were lost for every $1000 \mathrm{~kg}$ of FFB processed using the industrial route while 0.0056 $\mathrm{kg}, 0.0032 \mathrm{~kg}, 0.014 \mathrm{~kg}$, and $0.0051 \mathrm{~kg}$ were lost using small-scale routes, respectively. The smallest losses of $0.0034 \mathrm{~kg}$ of $\mathrm{CPO}, 0.002 \mathrm{~kg}$ of $\mathrm{PK}, 0.0087 \mathrm{~kg}$ of MF, and $0.0031 \mathrm{~kg}$ of PKS were obtained using the traditional route. The losses with the small-scale and traditional routes for every $1000 \mathrm{~kg}$ of FFB processed were very small and insignificant making them quite efficient in ensuring the fruits are recovered from the bunch. 


\section{Table 2}

Crude palm oil (CPO), palm kernel (PK), palm kernel shell (PKS) and mesocarp fibre (MF) lost for every $1000 \mathrm{~kg}$ of fresh fruit bunch processed for the industrial (I), small-scale $(\mathrm{S})$ and traditional $(\mathrm{T})$ routes of fresh fruit bunch (FFB) processing

\begin{tabular}{|c|c|c|c|c|c|c|c|c|c|c|c|c|}
\hline \multirow{2}{*}{$\begin{array}{l}\text { Day } \\
\text { number }\end{array}$} & \multicolumn{3}{|c|}{$\mathrm{CPO}(\mathrm{kg})$} & \multicolumn{3}{|c|}{ PK (kg) } & \multicolumn{3}{|c|}{ PKS (kg) } & \multicolumn{3}{|c|}{$\mathrm{MF}(\mathrm{kg})$} \\
\hline & $\mathrm{I}$ & $S$ & $\mathrm{~T}$ & I & $S$ & $\mathrm{~T}$ & I & $S$ & $\mathrm{~T}$ & I & $\mathrm{S}$ & $\mathrm{T}$ \\
\hline 1 & 21.61 & 0.0044 & 0.0002 & 12.49 & 0.0026 & 0.0001 & 19.83 & 0.0041 & 0.0002 & 55.72 & 0.0110 & 0.0005 \\
\hline 2 & 24.66 & 0.0019 & 0.0021 & 14.26 & 0.0011 & 0.0012 & 22.63 & 0.0018 & 0.0019 & 63.58 & 0.0049 & 0.0054 \\
\hline 3 & 27.69 & 0.0066 & 0.0024 & 16.00 & 0.0038 & 0.0014 & 25.40 & 0.0060 & 0.0022 & 71.37 & 0.0170 & 0.0061 \\
\hline 4 & 25.74 & 0.0087 & 0.0064 & 14.88 & 0.0050 & 0.0037 & 23.61 & 0.0080 & 0.0059 & 66.35 & 0.0220 & 0.0170 \\
\hline 5 & 32.29 & 0.0029 & 0.0018 & 18.67 & 0.0017 & 0.0010 & 29.63 & 0.0027 & 0.0017 & 83.25 & 0.0075 & 0.0047 \\
\hline 6 & 31.83 & 0.0097 & 0.0017 & 18.40 & 0.0056 & 0.0010 & 29.20 & 0.0089 & 0.0016 & 82.05 & 0.0250 & 0.0044 \\
\hline 7 & 27.50 & 0.0055 & 0.0047 & 15.90 & 0.0032 & 0.0027 & 25.23 & 0.0050 & 0.0043 & 70.90 & 0.0140 & 0.0120 \\
\hline 8 & 37.66 & 0.0050 & 0.0041 & 21.77 & 0.0029 & 0.0023 & 34.55 & 0.0045 & 0.0037 & 97.08 & 0.0130 & 0.0100 \\
\hline 9 & $\begin{array}{l}25.05 \\
0\end{array}$ & 0.0058 & 0.0044 & 14.48 & 0.0033 & 0.0025 & 22.98 & 0.0053 & 0.0040 & 64.58 & 0.0150 & 0.0110 \\
\hline 10 & 35.29 & 0.0052 & 0.0062 & 20.40 & 0.0030 & 0.0036 & 32.38 & 0.0048 & 0.0056 & 90.97 & 0.0140 & 0.0160 \\
\hline Average & 28.93 & 0.0056 & 0.0034 & 16.72 & 0.0032 & 0.0020 & 26.54 & 0.0052 & 0.0031 & 74.59 & 0.0140 & 0.0087 \\
\hline
\end{tabular}




\section{Table 3}

Mean ( \pm standard error) of the crude palm oil (CPO), palm kernel (PK), palm kernel shell (PKS), and mesocarp fibre (MF) lost for every $1000 \mathrm{~kg}$ of fresh fruit bunch (FFB) processed using the industrial, small-scale and traditional routes for 10 days of measurement ${ }^{c}$.

\begin{tabular}{|c|c|c|c|c|}
\hline Routes & CPO (kg) & Palm kernel (kg) & $\begin{array}{l}\text { Palm Kernel Shell } \\
(\mathrm{kg})\end{array}$ & $\begin{array}{l}\text { Mesocarp fibre } \\
(\mathrm{kg})\end{array}$ \\
\hline Industrial & $28.93 \pm 1.62 a$ & $16.73 \pm 0.94 a$ & $26.54 \pm 1.49 a$ & $74.59 \pm 4.18 \mathrm{a}$ \\
\hline $\begin{array}{l}\text { Small- } \\
\text { scale }\end{array}$ & $0.0056 \pm 0.00075 b$ & $0.0032 \pm 0.00043 b$ & $0.0051 \pm 0.00068 b$ & $0.014 \pm 0.0019 \mathrm{~b}$ \\
\hline Traditional & $0.0034 \pm 0.00065 b$ & $0.0020 \pm 0.00038 \mathrm{~b}$ & $0.0031 \pm 0.00059 b$ & $0.0087 \pm 0.0017 \mathrm{~b}$ \\
\hline
\end{tabular}


Under the industrial route, bunches are sterilized same day they are harvested while under both the small-scale and traditional routes, bunches can stay for few days enabling the fruits to loosen from the spikelets. The longer the fruits are allowed to stay before sterilization the more the free fatty acids content in the palm oil (Tan et al. 2009). Other factors responsible for increase in free fatty acids are bruising of the fruits and time lapse after bruising (Chong \& Sambanthamurthi 1993). The free fatty acids of palm oil processed using the small-scale and traditional routes are higher than in the industrial route. Free fatty acids level is an important quality indicator of palm oil (Saad et al. 2007). It is used to measure both quality of palm oil for food consumption and non-food uses (Hayyan et al. 2013). Low grade CPO has free fatty acids more than 5\% (Hayyan et al. 2013). Therefore, sterilization immediately after harvest with the industrial processing route offers the best in processing FFB. Another interesting operation is splitting bunches into quarters, and into spikelets and stalks for small-scale and traditional routes, respectively. The size reduction makes it easier for stalks and spikelets from traditional route (Figure 3 a) and the quartered bunches from small-scale route (Figure 3 b) to dry faster under ambient temperature and can easily be used as fuel. Sterilized EFB (Figure $3 \mathrm{c}$ ) from industrial route with considerable quantity of oil takes longer time to dry unless enormous amount of energy is invested. Additionally, the fruit attached to EFB, which is more with industrial route, limits its use. The volume generated at any time using the industrial route and availability of shells and fibre limits the use of EFB as fuel. However, the use of EFB for fuel generation remains an energy option for increased power generation and it is being encouraged in Malaysia (Husain et al. 2003). 
Figure 3

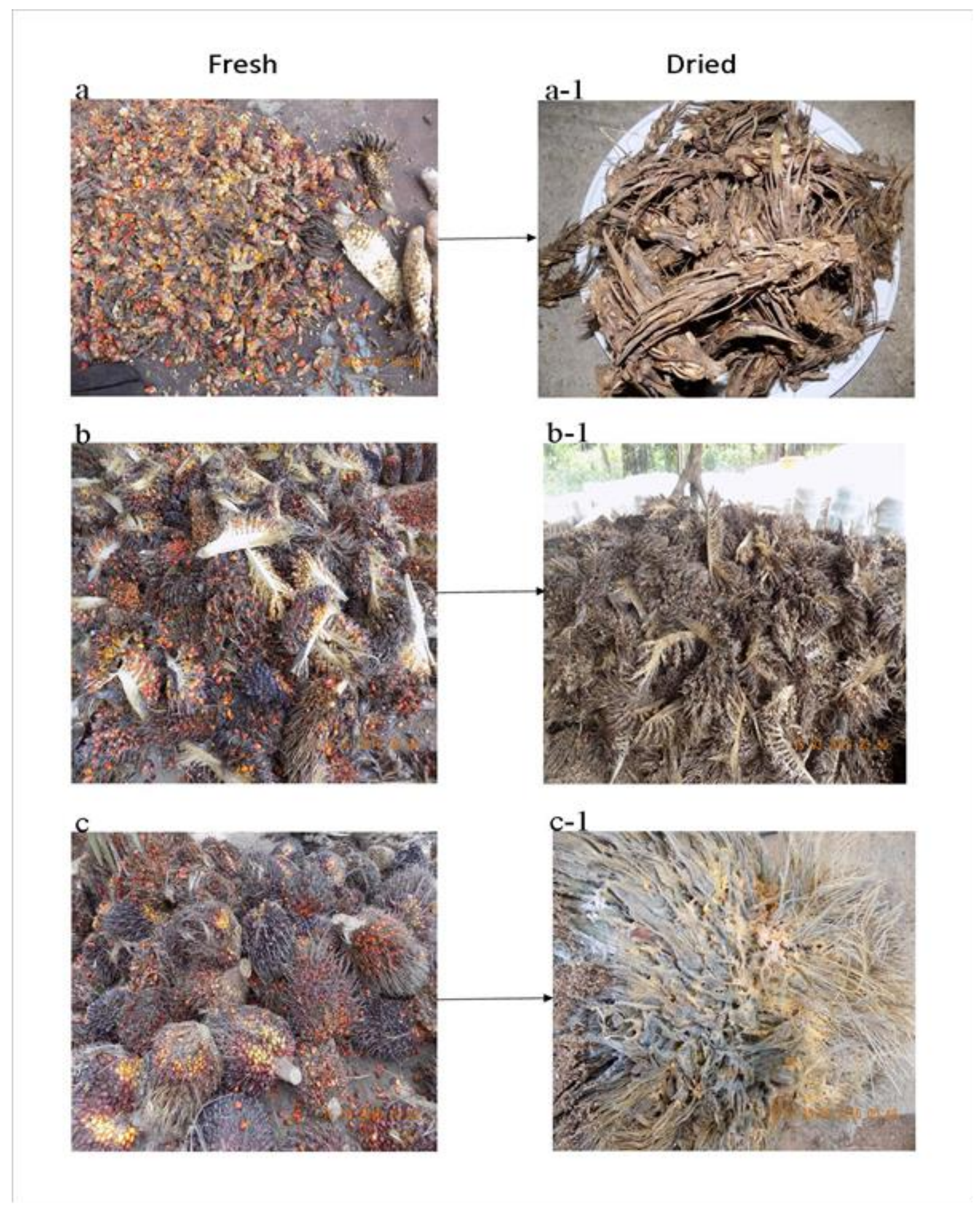


Energy losses

The low heating values (LHV) and bulk densities of the EFB, MF and PKS were determined as 14500, 17850, and $17340 \mathrm{kJkg}^{-1}$ and 144, 255, and $715 \mathrm{kgm}^{-3}$, respectively.

The values of MF and PKS lost for each processing route was estimated in kWh using $1.19 \mathrm{kWh}$ and $1.16 \mathrm{kWh}$ as energy value for every $1 \mathrm{~kg}$ each of MF and PKS respectively. Therefore, $89 \mathrm{kWh}$ of energy value was lost from MF and $31 \mathrm{kWh}$ of energy was lost from PKS with the industrial route. An insignificant 0.02 and 0.01 kWh energy values from MF, 0.006 and 0.004 kWh energy values from PKS were lost for the small-scale and traditional routes respectively.

From the calculations shown in Tables 4, the energy loss with the industrial route is huge. Data from one of the mills (industrial route -60 tonshour $^{-1}$ mill) visited in 2015 showed that about 95 kt of FFB was processed in 2014. From Table 4 the value of EFB produced was estimated as $29 \mathrm{kt}$, which were all deposited in the estate as manure. The total energy source produced in 2014 in the mill was estimated as $78 \mathrm{GWh}$ of which $35 \mathrm{GWh}$ was lost through the poor processing of FFB. The World Bank report on electrical power consumption in Nigeria in 2014 was $142 \mathrm{kWh}$ per capita compared to the corresponding figures of the United States (12088 kWh), and United Kingdom (5407 kWh). From Table 4 the total lost biomass from a single industrial mill in Nigeria in 2014 per capital, considering population of 182 million people from the National Population Commission Nigeria was $0.191 \mathrm{kWh}$ in its energy value. The lost energy value is huge and would have been enough to power 3 million homes (10 $000 \mathrm{MWh}$ per million homes). Electricity consumption and steam demand for the production of $1 \mathrm{~kg}$ of palm oil according to Sulaiman et al. (2011) which are $0.075-0.1 \mathrm{kWh}$ and $2.5 \mathrm{~kg}$, respectively can be met by burning 
$0.3-0.4 \mathrm{~kg}$ oil palm wastes. Therefore, over $29 \mathrm{kt}$ of EFB deposited in the plantation could be used to produce about $72 \mathrm{kt}$ of palm oil. 


\section{Table 4}

Data on production for 2014 of one of the oil mills in South Eastern Nigeria (approximate values). This mill has a capacity to process 60 tons of fresh fruit bunch per hour. ${ }^{¥}$ Actual value produced by the mill in 2014 was about $19 \%$ of FFB processed. "Used mainly as animal feed. $1 \mathrm{~kg}$ of EFB $=0.97 \mathrm{kWh}$. Empty fruit bunch (EFB), crude palm oil (CPO), palm kernel (PK), mesocarp fibre (MF), palm kernel shell (PKS)

\begin{tabular}{lllll}
\hline Parameter & $\begin{array}{l}\text { Estimated } \\
\text { quantity } \\
\text { produced, kt }\end{array}$ & $\begin{array}{l}\text { Estimated } \\
\text { quantity lost, kt }\end{array}$ & $\begin{array}{l}\text { Estimated Value } \\
\text { produced in } \\
\text { GWh }\end{array}$ & $\begin{array}{l}\text { Estimated } \\
\text { Value lost in } \\
\text { GWh }\end{array}$ \\
\hline EFB & 29 & 29 & 35 & 35 \\
* $¥ \mathrm{CPO}$ & 10 & 0.30 & - & - \\
${ }^{*} \mathrm{PK}$ & 6 & 0.10 & - & - \\
$\mathrm{MF}$ & 27 & 2 & 32 & 0.15 \\
PKS & 9 & 0.26 & 11 & 0.0007 \\
Total & $\mathbf{8 1}$ & $\mathbf{3 2}$ & $\mathbf{7 8}$ & $\mathbf{3 5}$ \\
\hline
\end{tabular}


Environmental impact

The industrial route leads to the generation of more POME, which constitutes environmental hazard, and with high-energy requirement and cost to process and dispose. POME from small-scale and traditional routes are minimal and manageable. The bulk of the POME is from the water used in the sterilization of FFB using the industrial route. The more the current sterilization method with the industrial route is used in FFB processing, the more POME generated and EFB of high moisture content. POME disposal ponds pose a serious environmental threat with release of greenhouse gas (methane) and nutrient into surface and underground water (Schuchardt et al. 2007). Each ton of CPO produced according to Schuchardt et al. (2007) leads to the emission of $32.9 \mathrm{~kg}$ of methane, which is about $98.7 \mathrm{~kg}$ of methane from Table 4. Poor decomposition of empty fruit bunch leads to the release of methane and $\mathrm{N}_{2} \mathrm{O}$ up to 0.23 ton (carbon-dioxide equivalent) $\mathrm{CO}_{2}$ eq per ton of fresh fruit bunch processed according to Elbersen et al. (2013). This is equivalent to the release of 6,670 tons $\mathrm{CO}_{2} \mathrm{eq}$ of methane and $\mathrm{N}_{2} \mathrm{O}$ of the $29 \mathrm{kt}$ of EFB disposed from one of the industrial mill as shown in Table 4 . This value equals $0.2 \%$ of United States of America's greenhouse gas emission from wastes composting in 2014 and 2015 (US EPA 2017). According to Krishnan et al. (2016) the co-composting of EFB and POME can lead to the reduction of greenhouse gas emission by $76 \%$. Positive changes towards improving the quality of EFB from industrial route will involve use of less water and therefore low amount of POME will be generated. Tan et al. (2009) offered an insight on the need to avoid sterilization during processing of FFB. Sukaribin and Khalid (2009) reported on the effectiveness of sterilization of oil palm bunch using microwave technology aimed at reducing oil loss and stripping efficiency. Similarly, Cheng et al. (2011) observed that using microwave for FFB 
processing improved the quality of CPO. In some countries, incineration of EFB is forbidden because of smoke pollution (Schuchardt et al. 2007). This is largely due to the high moisture content of EFB from the industrial route, which requires enormous energy to dry. Though EFB dumped in the plantations over time decays and add nutrient to the soil, it also adds pressure to the land especially in combination with the ash from the boilers, which follows the same disposal route. In Nigeria with low power production, using EFB for energy purposes is a promising option.

Socio - Economic impact

The utilisation of FFB wastes especially fibre and shell is a catalyst to increased socio-economic activities in localities where FFB are processed. PKS, MF, and EFB have been found very useful in different ways and forms but most notably in heat and power generation. EFB with large number of fruits has limitation on its utilisation for energy purposes.

Cost of processing FFB using the small-scale route was compared with the value of CPO. Labour cost for processing 125 bunches is 5950 Nigeria Naira (N) which is equivalent to $\$ 21(\$ 1=\mathrm{N} 282)$. At an average weight of $8.9 \mathrm{~kg}$ of a bunch, labour court of processing $1000 \mathrm{~kg}$ is N5348 (\$19). In terms of benefit, the value of $20 \mathrm{~kg}$ of oil is $\mathrm{N} 5320$ (\$19) therefore, $28.93 \mathrm{~kg}$ of oil lost per $1000 \mathrm{~kg}$ of FFB processed from the industrial route is N7695 (\$27). The value (\$27) of lost CPO per $1000 \mathrm{~kg}$ of FFB using industrial route can offset the cost (\$19) of processing $1000 \mathrm{~kg}$ of FFB using the small-scale route. This represents a significant amount of money in terms of employment and economic value at the local communities where FFB are processed. Small-scale and traditional routes of processing FFB discourage high productivity and quality CPO as it were. Obviously, the industrial route offers more 
opportunities in employment and wealth generation because of amount of FFB that can be processed per hour of operation. A balance between the benefits associated with the current industrial route and the losses is very important with the increasing demand for utilisation of biomass in energy production.

The small-scale and traditional routes are less wasteful but the palm oil from industrial route is of higher standard because the fruits are processed faster and in shorter time frame between harvest and sterilization. It can take few hours to process the fruits using the industrial route but minimum of 4 days to process the fruits using the small-scale and traditional routes. The lower grade EFB from the industrial route makes available a waste that can only be disposed of in the oil palm plantation because of its poor quality as energy source and therefore limits its value. In the small-scale level, EFB produced is used as fuel, which represent an economic benefit at that level.

Although, sterilization and stripping of fruits are important steps in FFB processing but contribute more to POME generated and the losses as the above study has shown, new approaches on sterilization and stripping of fruits are needed. This is important not only to process the fruits at a faster rate with high quality CPO as the industrial route can do but also to increase the chances of threshing all the fruits from the bunch like the small-scale and traditional routes. Additionally, to make it easier to use EFB as fuel in terms of low moisture content and high bulk density which could increase the transportation and utilisation of EFB cost efficiently beyond the point of generation.

Figure 4 is a process model for increased utilisation of EFB and a catalyst for increased economic activity and power generation in Southern Nigeria where the FFB is processed. This will ensure recovery of all the fruits and drying of EFB for use 
as fuel by the locals who also supply FFB to industrial processors creating a closed loop system. The abundance of fuel due to availability of EFB will create an opportunity for independent power producers, which can also be spinoffs of oil palm mills. 
Figure 4

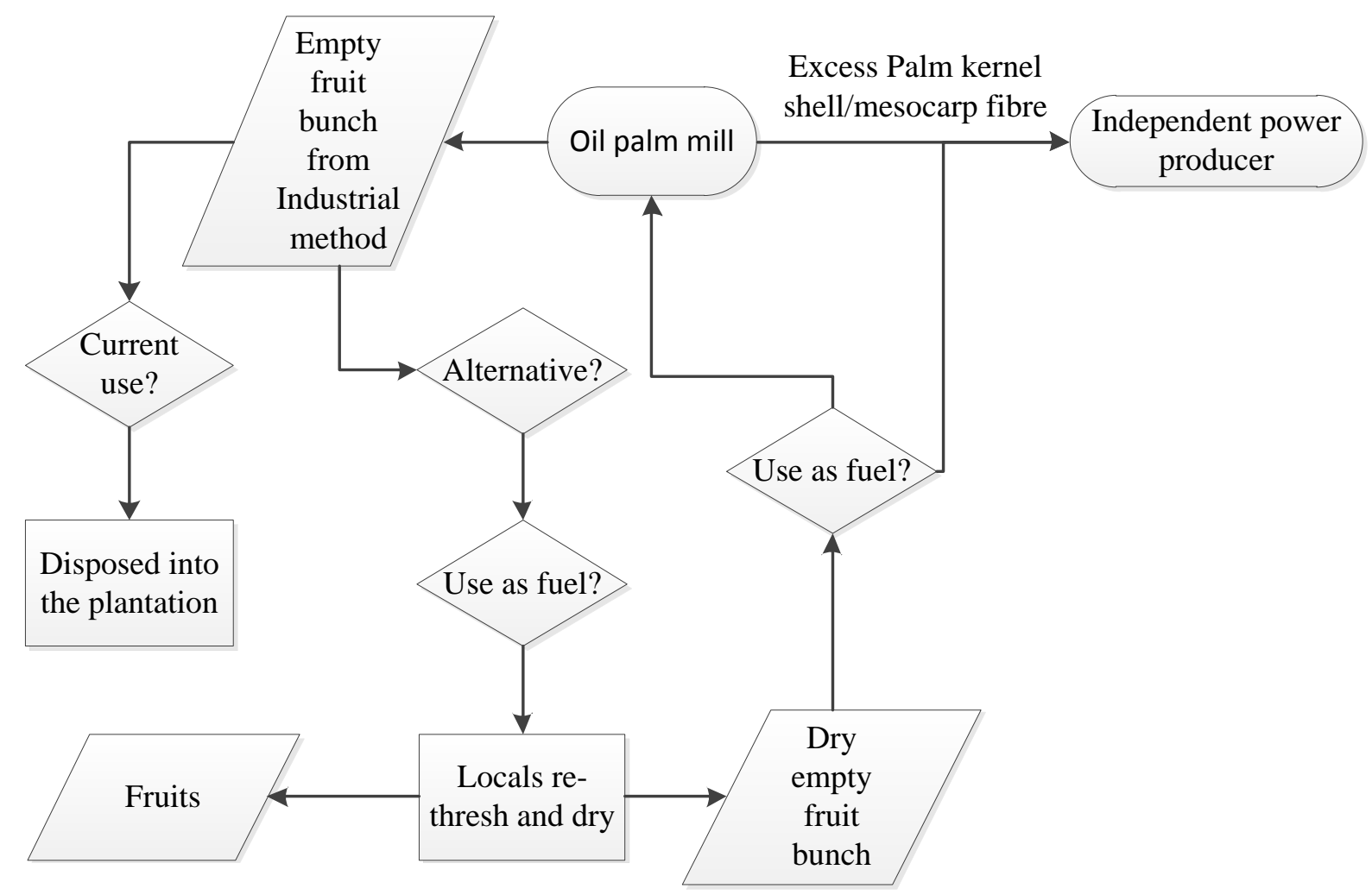




\section{Conclusions}

The results of the analysis of losses due to FFB processing routes showed that 29 $\mathrm{kg}$ of crude palm oil (CPO), $18 \mathrm{~kg}$ of palm kernel, $75 \mathrm{~kg}$ of mesocarp fibre (MF), and $27 \mathrm{~kg}$ of palm kernel shell (PKS) were lost for every $1000 \mathrm{~kg}$ of FFB processed with the industrial route, whereas $0.0056 \mathrm{~kg}, 0.0032 \mathrm{~kg}, 0.0014 \mathrm{~kg}$, and $0.0051 \mathrm{~kg}$ were lost with small-scale route, respectively. The equivalent of 6,670 tons oCO2eq of methane and $\mathrm{N}_{2} \mathrm{O}$ is released due to the disposal 29000 tons of EFB from one oil palm mill. The local labourers earn about $\$ 19$ in processing $1000 \mathrm{~kg}$ of FFB in the small-scale route, which is about the same value of fruits lost in the industrial route; it is therefore recommended that threshed EFB from industrial route be supplied to the local labourers for re-threshing and drying. The dried EFB will be sent back to the mills, and independent power producers which can be offshoot companies from the oil palm mills and considering the lost energy value which is enough to power 3 million homes (10 $000 \mathrm{MWh}$ per million homes), neighbouring communities can be powered using this model. Additionally, the co-composting of EFB will reduce the effects of poor decomposition of EFB. The enactment of laws against disposal of EFB particularly will encourage efforts towards better ways of processing oil palm fresh fruit bunch.

\section{Acknowledgements}

The Tertiary Education Trust Fund (TETFUND), Nigeria and the Imo State Polytechnic Umuagwo, Ohaji Imo State, Nigeria supported this work. 


\section{References}

Ali FS, Shamsudin R \& Yunus R (2014) The Effect of Storage Time of Chopped Oil Palm Fruit Bunches on the Palm Oil Quality. Agriculture and Agricultural Science Procedia, 2, 165-172. http://doi.org/10.1016/j.aaspro.2014.11.024

Aziz M, Kurniawan T, Oda T \& Kashiwagi T (2017) Advanced power generation using biomass wastes from palm oil mills. Applied Thermal Engineering, 114, 1378-1386. http://doi.org/10.1016/j.applthermaleng.2016.11.031

Babatunde OO, Ige MT \& Makanjuola GA (1988) Effect of sterilization on fruit recovery in oil palm fruit processing. J. Agric. Engin Res., 41, 75-79. http://doi.org/10.1016/0021-8634(88)90190-4

Cheng SF Nor LM \& Chuah CH (2011) Microwave pretreatment: A clean and dry method for palm oil production. Industrial Crops and Products, 34(1), 967-971. http://doi.org/10.1016/j.indcrop.2011.03.002

Chong CL \& Sambanthamurthi R (1993) Effects of mesocarp bruising on the rate of free fatty acid release in oil palm fruits. International Biodeterioration \& Biodegradation, 31, 65-70. http://doi.org/10.1016/0964-8305(93)90015-T Elbersen HW, Meesters KPH \& Bakker RRC (2013) Valorization of palm oil ( mill ) residues. Identifying and solving the challenges. Wageningen.

FAOSTAT (2017) FAO Crops Statistics Database. from http://faostat3.fao.org/ browse/Q/QC/E (accessed April 12, 2017)

Hayyan A, Mjalli FS Hashim1 MA, Hayyan1 M \& AINashef IM (2013) Conversion of free fatty acids in low grade crude palm oil to methyl esters for biodiesel production using chromosulfuric acid. Bulgarian Chemical Communications, 45(3), $394-399$.

Husain Z, Zainal ZA \& Abdullah MZ (2003) Analysis of biomass-residue-based 
cogeneration system in palm oil mills. Biomass and Bioenergy, 24, 117-124. http://doi.org/10.1016/S0961-9534(02)00101-0

Kabir G, Din ATM \& Hameed BH (2017) Pyrolysis of oil palm mesocarp fiber and palm frond in a slow-heating fixed-bed reactor: A comparative study.

Bioresource Technology, 241, 563-572.

http://doi.org/10.1016/j.biortech.2017.05.180

Krishnan Y Phun C, Bong C \& Farhana N (2016) Co-composting of palm empty fruit bunch and palm oil mill ef fluent: Microbial diversity and potential mitigation of greenhouse gas emission. Journal of Cleaner Production, 146, 1-7. http://doi.org/10.1016/j.jclepro.2016.08.118

Lee XJ, Lee LY, Gan S, Thangalazhy-Gopakumar S \& Ng HK (2017) Biochar potential evaluation of palm oil wastes through slow pyrolysis: Thermochemical characterization and pyrolytic kinetic studies. Bioresource Technology, 236, 155-163. http://doi.org/10.1016/j.biortech.2017.03.105

Ohimain El, Izah SC \& Obieze FAU (2013) Material-mass Balance of Smallholder Oil Palm Processing in the Niger Delta , Nigeria. Advance Journal of Food Science and Technology, 5(3), 289-294.

Schuchardt F, Wulfert KD, Darnoko \& Herawan T (2007) Effect of new palm oil mill processes on the EFB and POME utilisation. In Chemistry and Technology Conference PIPOC 2007 (pp. 44-57). Kuala Lumpur.

Shahbaz M, Yusup S, Inayat A, Onoja D \& Pratama A (2017) Optimization of hydrogen and syngas production from PKS gasification by using coal bottom ash. Bioresource Technology, 241, 284-295.

Sukaribin N \& Khalid K (2009) Effectiveness of sterilisation of oil palm bunch using microwave technology. Industrial Crops and Products, 30, 179-183. 
http://doi.org/10.1016/j.indcrop.2009.05.001

Sulaiman F, Abdullah N, Gerhauser H \& Shariff A (2011) An outlook of Malaysian energy, oil palm industry and its utilisation of wastes as useful resources. Biomass and Bioenergy, 35, 3775-3786. http://doi.org/10.1016/j.biombioe.2011.06.018

Taiwo KA, Owolarafe OK, Sanni LA, Jeje JO, Adeloye K \& Ajibola OO (2000) Technological assessment of palm oil production in Osun and Ondo states of Nigeria. Technovation, 20, 215-223.

Tan CH, Ghazali HM, Kuntom A, Tan CP \& Ariffin AA (2009) Extraction and physicochemical properties of low free fatty acid crude palm oil. Food Chemistry, 113, 645-650. http://doi.org/10.1016/j.foodchem.2008.07.052 US EPA 430-P-17-001 (2017) Inventory of U.S. Greenhouse Gas Emissions and Sinks 1990-2015. https://www.epa.gov/ghgemissions/inventory-us-greenhousegas-emissions-and-sinks-1990-2015 (accessed June 20, 2017)

Zainal NH, Aziz AA, Idris J, Mamat R, Hassan MA, Bahrin EK \& Abd-Aziz S (2016) Microwave-assisted pre-carbonisation of palm kernel shell produced charcoal with high heating value and low gaseous emission. Journal of Cleaner Production, 2945-2949. http://doi.org/10.1016/j.jclepro.2016.10.176 


\section{Figure Captions}

Figure 1 Map of Nigeria's regions showing the area of interest in two states of Imo (Ohaji/Egbema) and Rivers (Ikwere).

Figure 2 Flow chart of industrial, small-scale, and traditional route of fresh fruit bunch processing showing points of generation of waste. Solid box $=$ Process, Dashed box = wastes/output, EFB - empty fruit bunch, CPO - crude palm oil, POME - palm oil mill effluent, ES - empty spikelets, MF - mesocarp fibre, PKS - palm kernel shell, $\mathrm{T}$ - Traditional route, $\mathrm{S}$ - small-scale route, I - industrial route.

Figure 3 (a) Fresh spikelets and stalk of fresh fruit bunch separated in the traditional route, (a-1) natural drying empty spikelets; (b) fresh quartered empty fruit bunches from a small-scale route in Nigeria, (b-1) natural drying empty quartered bunch; (c) fresh fruit bunch, (c-1) natural drying empty fruit bunch processed from an industrial route mill in Nigeria.

Figure 4 Process model for increased utilisation of EFB and a catalyst for increased economic activity and power generation in the Southern Nigeria. 